\title{
Staged Approach for Stent-Assisted Coiling of Cerebral Aneurysms after Failure of Initial Intra-Saccular Catheterization
}

\author{
Abdulrahman Hamad Al-Abdulwahhab, $\mathrm{MD}^{1}$, Deok Hee Lee, $\mathrm{MD}, \mathrm{PhD}^{2}$, Yunsun Song, $\mathrm{MD}^{2}$, \\ Dae Chul Suh, MD, PhD ${ }^{2}$ \\ ${ }^{1}$ Diagnostic and Interventional Radiology Department, Imam Abdulrahman Bin Faisal University, King Fahd Hospital of the University, Khobar \\ City, Saudi Arabia \\ ${ }^{2}$ Department of Radiology, Asan Medical Center, University of Ulsan College of Medicine, Seoul, Korea
}

Purpose: Microcatheter navigation into an aneurysm sac can present difficulties through negative interactions between the deployed stent mesh and microcatheter. We hypothesized that endothelialization of the stent mesh would minimize these interactions. We aimed to assess the feasibility of staged coiling after stenting by reviewing our experiences with unavoidably staged embolization cases.

Materials and Methods: Between 2011 and 2019, 7 patients (mean age 57.2 years, range 49-76 years) including 5 females, experienced 9 unruptured aneurysms treated with staged stenting and coiling due to unstable microcatheter navigation into the aneurysm after stent placement. The aneurysms were in the paraclinoid internal carotid artery (ICA) $(n=3)$, ophthalmic origin ICA $(n=1)$, superior cerebellar artery origin $(n=2)$, basilar tip $(n=2)$, and the middle cerebral artery bifurcation $(n=1)$. The stents used were the Neuroform Atlas $(n=4)$, Neuroform EZ $(n=2)$, and Low-profile Visualized Intraluminal Support Blue $(n=1)$.

Results: The mean interval between stenting and coiling was 15 weeks (range, 12-21 weeks). The average navigation time between the first roadmap imaging and microcatheter insertion in the sac was 14 minutes (range, 8-20 minutes). One aneurysm was occluded without further coiling on follow-up. Staged coiling successfully treated the remaining aneurysms $(n=8)$. No complications were identified.

Conclusion: In cases of difficult intra-saccular catheterization, intentional staged coiling may be a feasible option for stent-assisted coiling of the cerebral aneurysms.

Key Words: Cerebral aneurysm; Intracranial aneurysm; Stent; Therapeutic embolization

\section{INTRODUCTION}

Stent-assisted coiling (SAC) is a well-established option for the treatment of intracranial complex and broad-necked aneurysms, yielding higher rates of complete occlusion. ${ }^{1,2}$ Various types of stents with different properties have been developed, including laser-cut stents with open- or closed-cell designs as well as braided stents. ${ }^{3}$ Among these, low-profile self-expandable stents are relatively safe and allow easier delivery manipulation and deployment through

\section{Correspondence to:} Deok Hee Lee, MD, PhD Department of Radiology, Asan Medical Center, University of Ulsan College of Medicine, 88 Olympic-ro 43-gil, Songpa-gu, Seoul 05505, Korea Tel: +82-2-3010-5944 Fax: +82-2-476-0090

E-mail:dhlee@amc.seoul.kr

Received: October 28, 2020 Revised: January 31, 2021 Accepted: February 3, 2021
Copyright $\odot 2021$ Korean Society of Interventional Neuroradiology

This is an Open Access article distributed under the terms of the Creative Commons Attribution Non-Commercial License (http://creativecommons.org/licenses/by-nc/4.0) which permits unrestricted non-commercial use, distribution, and reproduction in any medium, provided the original work is properly cited. 
tortuous vessels. ${ }^{4,5}$

Treatment with SAC may occasionally show intra-procedural difficulties due to restriction in the swift navigation of the coil delivery microcatheter through the stent lumen and the entry of aneurysmal sac; this may increase the procedural difficulty and subsequently increase the procedure risk. Although the incidence of procedural abortion due to this mechanism is decreasing, intra-procedural technical difficulties may still be encountered as a result.

We hypothesized that such navigation difficulties would be minimized if the stent was covered with a neo-intima layer and fixed into the vessel wall after a certain time. Thus, the purpose of this study was to evaluate the feasibility of staged coiling in cases involving initial failure of intra-saccular aneurysm catheterization during SAC.

\section{MATERIALS AND METHODS}

\section{Patient population}

The local Instituational Review Board of Asan Medical Center approved this retrospective study based on a prospectively collected database. We reviewed the data on all patients with intracranial aneurysms who underwent staged SAC embolization procedures between July 2011 to December 2019. The multistage approach was defined as a stepwise procedure in which the stent was initially deployed without coiling and complete embolization was performed later in a separate session.

We included 7 patients with 9 unruptured aneurysms. Patient data, including clinical presentation, radiological evaluation, and postoperative assessment, were obtained from the database connected to the electronic medical record system. Patients' demographic features, including age and sex, aneurysmal location, and size were collected (Table 1). All aneurysms were analyzed based on the 3D reconstruction. The largest aneurysm diameter was measured in millimeters and categorized as small ( $<7 \mathrm{~mm})$, medium (7-12 mm), large (>12-25 mm), and giant (>25 mm), according to the groups proposed by the International Study on Unruptured Intracranial Aneurysms (ISUIA). ${ }^{6}$

\section{Procedure}

Informed consent was obtained from all patients before the

Table 1. Clinical demography and procedures of staged stent-assisted coiling embolization in 7 patients

\begin{tabular}{|c|c|c|c|c|c|c|c|c|c|}
\hline $\begin{array}{l}\text { Case } \\
\text { number }\end{array}$ & $\begin{array}{l}\text { Age }(y) / \\
\text { Sex }\end{array}$ & $\begin{array}{l}\text { Symptoms at } \\
\text { presentation }\end{array}$ & $\begin{array}{c}\text { Type of } \\
\text { aneurysm }\end{array}$ & $\begin{array}{l}\text { Aneurysm } \\
\text { sized } \\
\text { according } \\
\text { to ISUIA }\end{array}$ & $\begin{array}{l}\text { Location of } \\
\text { aneurysm }\end{array}$ & Stent & $\begin{array}{l}\text { Time interval } \\
\text { between } \\
\text { staging } \\
\text { procedures }\end{array}$ & $\begin{array}{l}\text { Time from initial } \\
\text { road map to } \\
\text { first coil packing } \\
\text { (2nd procedure) }\end{array}$ & $\begin{array}{l}\text { Time from stent } \\
\text { insertion to the } \\
\text { final run (1st } \\
\text { procedure) }\end{array}$ \\
\hline 1 & $49 / F$ & Headache & $\begin{array}{c}\text { Saccular } \\
\text { aneurysm }\end{array}$ & $\begin{array}{l}\text { Small, } \\
6 \mathrm{~mm} \\
5 \mathrm{~mm}\end{array}$ & $\begin{array}{l}\text { Paraclinoid } \\
\text { ICA X2 }\end{array}$ & $\begin{array}{c}\text { Neuroform } \\
\text { EZ }\end{array}$ & $12 w k$ & $16 \min$ & $39 \min$ \\
\hline 2 & $50 / F$ & Headache & $\begin{array}{l}\text { Saccular } \\
\text { aneurysm }\end{array}$ & $\begin{array}{l}\text { Small, } \\
4 \mathrm{~mm}\end{array}$ & $\begin{array}{c}\text { Ophthalmic } \\
\text { ICA }\end{array}$ & $\begin{array}{c}\text { Neuroform } \\
\text { EZ }\end{array}$ & 16 wk & $20 \mathrm{~min}$ & $41 \mathrm{~min}$ \\
\hline 3 & $65 / M$ & Headache & $\begin{array}{l}\text { Saccular } \\
\text { aneurysm }\end{array}$ & $\begin{array}{l}\text { Small, } \\
3 \mathrm{~mm}\end{array}$ & SCA & LVIS blue & - & - & $35 \mathrm{~min}$ \\
\hline 4 & $61 / F$ & $\begin{array}{l}\text { Incidentally } \\
\text { discovered }\end{array}$ & $\begin{array}{l}\text { Saccular } \\
\text { aneurysm }\end{array}$ & $\begin{array}{l}\text { Small, } \\
7 \mathrm{~mm}\end{array}$ & $\begin{array}{l}\text { Paraclinoid } \\
\text { ICA }\end{array}$ & $\begin{array}{l}\text { Neuroform } \\
\text { Atlas }\end{array}$ & 14 wk & $8 \mathrm{~min}$ & $31 \mathrm{~min}$ \\
\hline 5 & $62 / F$ & Headache & $\begin{array}{l}\text { Saccular } \\
\text { aneurysm }\end{array}$ & $\begin{array}{l}\text { Medium, } \\
12 \mathrm{~mm}\end{array}$ & Basilar tip & $\begin{array}{c}\text { Neuroform } \\
\text { Atlas }\end{array}$ & $21 w k$ & $13 \mathrm{~min}$ & $34 \mathrm{~min}$ \\
\hline 6 & $76 / M$ & $\begin{array}{l}\text { Right-side } \\
\text { weakness }\end{array}$ & $\begin{array}{c}\text { Saccular } \\
\text { aneurysm }\end{array}$ & $\begin{array}{l}\text { Small, } \\
7 \mathrm{~mm}\end{array}$ & $\begin{array}{c}\text { MCA } \\
\text { bifurcation }\end{array}$ & $\begin{array}{c}\text { Neuroform } \\
\text { Atlas }\end{array}$ & $18 w k$ & $16 \mathrm{~min}$ & $28 \mathrm{~min}$ \\
\hline 7 & $49 / F$ & Headache & $\begin{array}{l}\text { Saccular } \\
\text { aneurysm }\end{array}$ & $\begin{array}{l}\text { Small, } \\
6 \mathrm{~mm} \\
4 \mathrm{~mm}\end{array}$ & $\begin{array}{l}\text { Basilar tip } \\
\text { and SCA }\end{array}$ & $\begin{array}{c}\text { Neuroform } \\
\text { Atlas }\end{array}$ & 12 wk & $10 \mathrm{~min}$ & $31 \mathrm{~min}$ \\
\hline
\end{tabular}

The parameters of these cases include patient demographics, clinical symptoms, aneurysm morphology and location, name of stent used, technical considerations during the procedures, and follow-up times for the two procedures.

M, male; F, female; ISUIA, International Study of Unruptured Intracranial Aneurysms; ICA, the internal carotid artery; SCA, the superior cerebellar artery; MCA, the middle cerebral artery; LVIS, Low-profile Visualized Intraluminal Support device. 
procedure. The patients were on dual antiplatelet therapy from at least 5-7 days before the operation (acetylsalicylic acid $100 \mathrm{mg}$ daily and clopidogrel $75 \mathrm{mg}$ daily without loading doses). After stenting, the patients continued to receive the dual antiplatelet therapy (aspirin and clopidogrel daily) for at least 2 months. Thereafter, daily intake of aspirin continued for at least 4-6 months unless contraindicated.

All endovascular procedures were performed under general anesthesia. Baseline serum activated coagulation time (ACT) was estimated after inserting the 6-F sheath, usually via the right common femoral artery access, and intravenous heparin was administered to achieve an ACT 1.5 to 2 times that of the baseline value depending on the patient's weight (50-70 U/kg), as per hospital protocol. A 6-F guiding catheter was flushed with continuous heparinized saline and placed around the petrous-cavernous internal carotid artery (ICA) or distal V2 segments of the vertebral artery, depending on the aneurysm location.

The technical methods for all stents were similar. All stents were advanced with appropriate microcatheters and deployed across the aneurysmal neck. We used self-expandable intracranial stents, including Neuroform Atlas (Stryker Neurovascular, Fremont, CA, USA), Neuroform EZ (Stryker Neurovascular), and Low-profile Visualized Intraluminal Support (LVIS) device blue (Microvention, Tustin, CA, USA).

All stents were deployed successfully and covered the aneurysmal neck. Next, we navigated into the stent lumen with a J-shaped micro-guidewire (Traxcess; Microvention) tip and a microcatheter (Excelsior SL10; Stryker Neurovascular) to minimize the interaction between the micro-guidewire and stent mesh. In cases showing technical difficulty in the catheterization of the aneurysm sac even after our best technical effort, we aborted the procedure to avoid arterial damage and deformation of the deployed stent.

We scheduled the following embolization session after a minimum of 3 months. The second session followed the same procedural preparation. Under the guidance of road maps, we advanced the microwire-guided microcatheter to the target aneurysm, crossing the already deployed stent mesh using a cell-through technique, and performed confirmatory microcatheter tip stabilization within the intra-saccular aneurysm. We then filled the aneurysmal sac with coils of different sizes until complete occlusion was observed on angiograms.

\section{Data analysis}

Since the procedural duration could be a good surrogate indicator of procedural difficulty, we estimated the times required for both the first stenting and the subsequent coiling stage procedures. Considering the retrospective nature of this study, accurate measurement of the procedural duration was not possible; however, we attempted to estimate the time as consistently as possible. The procedure time was calculated as the time taken for the microcatheter navigation into the aneurysm sac in the second-stage procedure, starting from the acquisition of the first roadmap image right after guiding catheter positioning until the insertion of the first frame coil. For the first stent staging procedure, we roughly estimated the time from stent insertion within the target vessel to the final angiogram.

We analyzed the causes of microcatheter resistance in crossing the stent, including anatomical and technical factors. We classified stent patency based on radiological outcome after stent deployment as complete stent patency or total or partial occlusion at the staged stent. We defined total occlusion when the anterograde flow showed complete obliteration, while partial occlusion was defined as when the anterograde flow was diminished but did not reach total obliteration. On other hand, complete stent patency was defined as complete anterograde flow within the stented vessel with no occlusion.

Data on complications such as thromboembolic events, defined as the clinical development of a temporary or permanent neurological deficit during or after the operation, and the findings of confirmatory imaging examinations, including magnetic resonance imaging (MRI) with diffusion-weighted image sequences, were obtained for assessment. Other complications, such as intra-procedural aneurysm rupture, hemorrhagic complications, and dissections, were also evaluated in both the initial and secondary stages of the procedures. Additionally, 90-day clinical outcomes were measured using the modified Rankin score (mRS), with favorable and unfavorable outcomes defined as scores of $0-2$ and 3-6, respectively.

Statistical analysis was performed using IBM SPSS Statistics for Windows, version 20.0 (IBM Corp., Armonk, NY). Variables were expressed as median values (interquartile range). Kruskal-Wallis $\mathrm{H}$ tests for cross-tabulation were used to investigate the differences in time required to perform the 2 procedures, with $\mathrm{P}<0.05$ defined as the criterion for statistical significance. 


\section{RESULTS}

The patients' mean age was 57.2 years (range, 49-76 years); there were 5 females and 2 males (female-to-male ratio, 5:2). The clinical presentations at the time of presentation included headache $(n=5)$ and right-side weakness $(n=1)$, while 1 patient was asymptomatic $(n=1)$.

The aneurysms were located in the paraclinoid ICA $(n=3)$, ophthalmic origin ICA $(n=1)$, superior cerebellar artery (SCA) origin basilar artery $(n=2)$, basilar tip $(n=2)$, and middle cerebral artery (MCA) bifurcation ( $n=1$ ) (Table 1). The location of the aneurysms can be classified as a side aneurysm ( $n=6$; paraclinoid ICA, ophthalmic ICA origin, superior cerebellar artery origin basilar artery aneurysms) or a bifurcation aneurysm ( $n=3$; basilar tip and MCA bifurcation aneurysms). Furthermore, the aneurysms were located in the greater curvature side of a parent artery curve $(n=6$; ophthalmic ICA origin, basilar tip X2, paraclinoid ICA X2, superior cerebellar artery origin basilar artery aneurysms) and located in the lesser curvature of the parent artery ( $n=3$; paraclinoid ICA, SCA origin basilar artery aneurysm and MCA bifurcation aneurysms).

We utilized self-expandable intracranial stents, including an open stent such as the Neuroform Atlas $(n=4)$ and Neuroform EZ ( $n=2)$, and a closed stent such as the LVIS blue $(n=1)$. One patient with a LIVS blue stent showed total aneurysm resolution due to the flow diverter effect.

The mean interval between stent staging and the complete coiling procedure was 15 weeks (range, 12-21 weeks). In our study, successful stent deployment in the target artery was achieved in all cases involving staged stent procedures with complete flow patency (7/7, 100\%). We used Excelsior SL-10 (Stryker, Kalamazoo, MI, USA) as the primary microcatheter. As per the location of each aneurysm in relation to the parent artery, the microcatheter's shape was used as primary curves (straight, 45, 90, and J shapes), or modified microcatheter tip curves by steaming to conform to the shape of the aneurysm sac opening. We used primary curved $45(n=2)$, primary curved $90(n=1)$, primary curved J shaped $(n=1)$, and straight tip $(n=1)$, and the rest used a steam complex microcatheter tip curve $(n=4)$.

We observed smooth navigation and great stability of the coil delivery microcatheter into the aneurysmal sac in the coiling stage, and that less time was required compared to that required for stent staging. Moreover, the mean estimated time between the first roadmap of the target vessel to the delivered microcatheter within the aneurysmal sac, crossing the stent mesh, was 14 minutes (range, 8-20 minutes) compared to a mean time of 34 minutes (range, 28-41 minutes) for the stenting procedure to access the stent mesh before procedure termination ( $\mathrm{P}=0.017$ ). No periprocedural thromboembolic events or intracranial hemorrhage were observed during intraoperative assessments or immediate postoperative MRI.

The remaining aneurysms showed complete coiling without any technical difficulties and no long-term complications. No residual or recanalized aneurysms were identified during magnetic resonance angiography follow-up. All patients had a favorable mRS (0-2) at discharge and at follow-up.

\section{DISCUSSION}

SAC is considered to be an effective method for endovascular treatment of intracranial aneurysms, with low rates of intraoperative and clinical complications. SAC of intracranial aneurysms is performed as a single- or multistage procedure based on the intraoperative circumstances or personal preference. ${ }^{7}$ However, only a few studies have described a multistage approach. ${ }^{1,7-9}$

In staged procedures, the stent is first deployed across the aneurysm neck and left to endothelialize for up to 12 weeks before the patient can undergo coil embolization. This staging ensures greater stability and less movement of the stent during coil packing. Moreover, the choice of intracranial stenting was mostly based on operator preference, compatibility with the delivered microcatheter, and the status of the vascular anatomy, which can improve navigability and ease of stent deployment. ${ }^{9}$ The results of our study revealed that multistage procedures were applicable to intracranial aneurysms that may present difficulties in establishing microcatheter stability, either for a cross stent or while creating a position for coil packing or for stent movement when struggling to pass the microcatheter through the stent struts. We did not observe any complications associated with this approach and achieved good clinical and radiological outcomes. We believe that the time between the staged stenting and completion of the coiling procedure allowed the stent to be in a stable position to prevent unavoidable movement by enhancing endothelialization and platelet activation. This enhancement may further stabilize the stent mesh against the wall, providing safer microcatheter manipulation and re- 
duced incidence of thromboembolic events. A large cohort study is needed to verify this theory as well as our finding that the multistage approach resulted in fewer periprocedural complications than a single-stage procedure, which may be attributed to the interval between stenting and coiling that may provide a sufficient stent insulation time to avoid complications?

Advancing a microcatheter into an aneurysm in SAC embolization using the cell-through technique does not always feel secure. The closed-cell stent design at the proximal end with a flaring end provides good trackability and enhances the cell-through technique by smoothly passing a microwire in the stent lumen. When a microwire cannot be advanced through the stent or is stuck in the struts, a microwire looping technique provides easy navigation through the inside of the stent lumen. In contrast, an open-cell stent design, with both ends flared, provides excellent stability to the vessel wall and wall apposition. Microcatheters and microwires can easily pass through the inside of the stent without irritating the struts. Nevertheless, once the aneurysm selection is made using the cell-through technique, the microcatheter is stuck within a cell of the stent, becoming very stable while inserting coils. Thus, patients with small-caliber, stenotic, or very tortuous parent arteries may be good candidates for this technique. ${ }^{10}$

Self-expanding stents provide more support in aneurysm packing, with an increased neck coverage ratio, in addition to improved treatment durability through a combination of flow diversion, parent vessel straightening, and fibroelastic tissue formation along the neck of the aneurysm. This helps prevent aneurysm recanalization by redirecting flow and facilitating endothelialization at the aneurysm neck. ${ }^{1,9}$ Another study suggested that hemodynamic changes after stent crossing of the aneurysmal sac play a role in changing the parent vascular configuration."1

In our study, we identified anatomical and technical factors that may influence the ability of a microcatheter to pass the stent mesh and cause difficulties in aneurysmal sac catheterization. The anatomical factors were closely and independently associated with the aneurysm location, which was further influenced by regional vascular flow and may have a complex geometry as seen in the communicating artery or MCA branching aneurysms. We believe that for aneurysms located in the greater curvature side of a curved parent artery, it is more often than not easier to catheterize them than locate the lesser curvature side, unless they are not in the direction of flow impacted (Table 1). Technical factors play an important role in microcatheter navigation through the stent, including the stability of the guiding catheter and the proximity to the aneurysm, which are important for achieving optimal control for microcatheter stabilization. Furthermore, steady guidance of the catheter over a great distance is necessary for sufficient sustenance of the devices, especially in tortuous vessels. The precise shaping of microcatheter tips to conform to the aneurysm's configuration is also a key factor for safe aneurysm embolization after crossing the stent. Proper shaping can reduce microcatheter resistance during its navigation. Moreover, the selection of an appropriate microcatheter size and tip flexibility are crucial, as different properties affect the navigation strategy to cross the stent mesh and the stabilization within the aneurysmal sac. Finally, stent selection also plays a role in the feasibility of microcatheter navigation through the pores of the stent mesh and conformation against the vessel wall. In comparison with laser-cut stents, braided stents caused difficulties while re-crossing the stent after deployment.

Stent deployment plays a role in modifying mechanical, hemodynamic, and biological properties. With respect to the biological properties, the reaction of the stent to the parent artery wall is influenced by multiple factors, including vascular intimal injury, vascular remodeling, inflammation, and the healing process. After stent implantation, the adventitia and medium layers respond to stent-induced alterations, leading to vessel wall remodeling and resulting in significant changes to its mechanical properties. Muscle fibroblasts in the media layer can shrink, migrate, and secrete extracellular matrix, leading to further fibrosis and subsequent decreased vascular compliance. ${ }^{12}$

The disadvantages of this approach include the long time required to complete aneurysm embolization, which is not favorable for the patient, and the requirement of unexpected staged stenting under general anesthesia. Nevertheless, we advise that since the operator is not in a rush to complete the procedure, he or she can stop before an unexpected event occurs and consider multi-staged SAC embolization.

This retrospective study included a small case series; thus, the effects of possible selection bias cannot be excluded. The results reflect the experience of a single neurovascular center with a specific technique and hospital medication protocol, all of which may differ from other centers. 


\section{CONCLUSION}

In cases showing difficulty in intra-saccular catheterization, intentional staged coiling may be a viable procedural option for SAC of cerebral aneurysms.

\section{Fund}

None.

\section{Ethics Statement}

The local Instituational Review Board of Asan Medical Center approved this retrospective study based on a prospectively collected database.

\section{Conflicts of Interest}

DCS has been the Editor-in-Chief of the Neurointervention since 2018. No potential conflict of interest relevant to this article was reported.

YS has been the Assistant Editor of the Neurointervention since 2019. No potential conflict of interest relevant to this article was reported.

No other authors has any conflict of interest to disclose.

\section{Author Contributions}

Concept and design: DHL. Analysis and interpretation: DHL, YS, and DCS. Data collection: AHA. Writing the article: DHL, AHA, YS, and DCS. Final approval of the article: DHL. Statistical analysis: AHA. Overall responsibility: DHL.

\section{ORCID}

Abdulrahman Hamad Al-Abdulwahhab:

https://orcid.org/0000-0003-4398-7864

Deok Hee Lee: https://orcid.org/0000-0003-0355-0449

Yunsun Song: https://orcid.org/0000-0003-4738-0533

Dae Chul Suh: https://orcid.org/0000-0003-1561-5596

\section{REFERENCES}

1. Biondi A, Janardhan V, Katz JM, Salvaggio K, Riina HA, Gobin YP. Neuroform stent-assisted coil embolization of wide-neck intracranial aneurysms: strategies in stent deployment and midterm follow-up. Neurosurgery 2007;61:460-468; discussion 468-469
2. Beuing O, Lenz A, Donitza A, Becker M, Serowy S, Skalej M. Stent-assisted coiling of broad-necked intracranial aneurysms with a new braided microstent (Accero): procedural results and long-term follow-up. Sci Rep 2020;10:412

3. Cho SH, Jo WI, Jo YE, Yang KH, Park JC, Lee DH. Bench-top comparison of physical properties of 4 commercially-available self-expanding intracranial stents. Neurointervention 2017;12:31-39

4. Behme D, Weber A, Kowoll A, Berlis A, Burke TH, Weber W. Low-profile Visualized Intraluminal Support device (LVIS Jr) as a novel tool in the treatment of wide-necked intracranial aneurysms: initial experience in 32 cases. J Neurointerv Surg 2015;7:281-285

5. Akmangit I, Aydin K, Sencer S, Topcuoglu OM, Topcuoglu ED, Daglioglu $E$, et al. Dual stenting using low-profile LEO baby stents for the endovascular management of challenging intracranial aneurysms. AJNR Am J Neuroradio/ 2015;36:323-329

6. Wiebers DO, Whisnant JP, Huston J 3rd, Meissner I, Brown RD Jr, Piepgras DG, et al.; International Study of Unruptured Intracranial Aneurysms Investigators. Unruptured intracranial aneurysms: natural history, clinical outcome, and risks of surgical and endovascular treatment. Lancet 2003;362:103-110

7. Lodi Y, Latorre J, El-Zammar Z, Swarnkar A, Gordon V, Whapham $J$, et al. Single stage versus multi-staged stent-assisted endovascular repair of intracranial aneurysms. J Vasc Interv Neurol 2011;4:24-28

8. Fiorella D, Albuquerque FC, Deshmukh VR, McDougall CG. Usefulness of the Neuroform stent for the treatment of cerebral aneurysms: results at initial (3-6-mo) follow-up. Neurosurgery 2005;56:1191-1201; discussion 1201-1202

9. Chalouhi N, Jabbour P, Singhal S, Drueding R, Starke RM, Dalyai RT, et al. Stent-assisted coiling of intracranial aneurysms: predictors of complications, recanalization, and outcome in 508 cases. Stroke 2013:44:1348-1353

10. Park KY, Jang CK, Lee JW, Kim DJ, Kim BM, Chung J. Preliminary experience of stent-assisted coiling of wide-necked intracranial aneurysms with a single microcatheter. BMC Neurol 2019;19:245

11. Huang QH, Wu YF, Xu Y, Hong B, Zhang L, Liu JM. Vascular geometry change because of endovascular stent placement for anterior communicating artery aneurysms. AJNR Am J Neuroradiol 2011;32:1721-1725

12. Wanke I, Forsting M. Stents for intracranial wide-necked aneurysms: more than mechanical protection. Neuroradiology 2008;50:991-998 